APA: Prieto Fetiva, C. H. (2020). ¿Cualquier interés democrático debe producir consecuencias jurídicas y políticas? Aportes para una reconciliación entre democracia y constitucionalismo. En O. A. Agudelo Giraldo (Ed.), Derechos humanos, democracia y poder judicial (págs. 75-100). Editorial Universidad Católica de Colombia. https://doi.org/10.14718/9789585133020.2020.4

Chicago: Prieto Fetiva, Camilo Humberto, “¿Cualquier interés democrático debe producir consecuencias jurídicas y políticas? Aportes para una reconciliación entre democracia y constitucionalismo.” En Derechos humanos, democracia y poder judicial editado por Oscar Alexis Agudelo Giraldo, 75-100. Bogotá: Editorial Universidad Católica de Colombia. doi: 10.14718/9789585133020.2020.4

\title{
¿CUALQUIER INTERÉS DEMOCRÁTICO DEBE PRODUCIR CONSECUENCIAS JURÍDICAS Y POLÍTICAS? APORTES PARA UNA RECONCILIACIÓN ENTRE DEMOCRACIA Y CONSTITUCIONALISMO*
}

\author{
Camilo Humberto Prieto Fetiva*
}

\section{Introducción}

En Colombia, desde finales de 2015 y hasta inicios de 2017, hubo un fuerte debate moral, político y, sobre todo, constitucional, que se dio gracias a una propuesta de la senadora Viviane Morales Hoyos. Esta buscaba, mediante referendo, permitir la adopción de menores de edad solo a parejas heterosexuales, lo que

\footnotetext{
* El presente escrito hace parte del trabajo de investigación realizado por el autor en el Grupo de Estudios Legales y Sociales "Phronesis", adscrito al Centro de Investigaciones de la Universidad Católica de Colombia (CISJUC), en el marco del proyecto titulado: Derechos Humanos, Interculturalidad y Ética Pública, bajo la dirección del profesor Oscar Alexis Agudelo Giraldo.

** Abogado y especialista en Derecho Constitucional y Administrativo de la Universidad Católica de Colombia. Candidato a magister en Justicia y Tutela de Derechos con énfasis en Teoría Jurídica y Filosofía del Derecho de la Universidad Externado de Colombia. Docente de la Universidad Católica de Colombia. Contacto: camilohumberto@hotmail.com, chprieto@ucatolica.edu.co.
} 
traería consigo que las parejas del mismo sexo, e incluso las personas solteras, no pudieran adoptar².

Para lograr su cometido, la senadora recaudó un total de dos millones ciento treinta y cinco mil firmas (Redacción Política, 2016). Sin embargo, el 10 de mayo de 2017, cumpliendo con el trámite legal establecido, la Comisión Primera de la Cámara de Representantes negó dicha iniciativa legislativa, acarreando consigo la imposibilidad de que esta llegase a las urnas (Redacción Política, 2017).

No obstante, en un supuesto de hecho, si la propuesta hubiese llegado a las urnas, probablemente habría prosperado, dado que Colombia es un país con una fuerte tradición conservadora y es de mayoría católica ${ }^{3}$. En este sentido, y a través del ejercicio democrático, es decir, de la imposición de las mayorías, la senadora Morales buscaba limitar la decisión de adoptar, o sea, coartar el ejercicio del derecho fundamental al desarrollo libre de la personalidad.

Esta situación revivió un viejo debate que, pese a tener sus orígenes en el siglo XVII, sigue vigente en los Estados democráticos actuales. Por un lado, se encuentran las denominadas posiciones constitucionalistas, que parten de la idea de limitar el poder legislativo, dado que este no puede transgredir normas de carácter constitucional, como son el principio de igualdad y los derechos fundamentales (Ferrajoli, 2016), los cuales se emplean en la generación de demarcaciones a la voluntad mayoritaria (Ferrajoli, 2009).

En contraposición a ellas se sitúan las llamadas perspectivas democráticas, que rechazan enfáticamente las posiciones nombradas previamente, debido a que la rigidez constitucional, pilar de las mismas -y que será desarrollado más adelante-, limita los poderes de las generaciones futuras y, a su vez, de la misma democracia política (Ferrajoli, 2009).

\footnotetext{
2 Téngase en cuenta que mediante Sentencia C-071 de 2015, la Corte Constitucional Colombiana permitió la adopción por parte de parejas del mismo sexo, siempre y cuando dicha solicitud recaiga en el hijo biológico de uno de los compañeros o compañeras permanentes. Igualmente, en la Sentencia C-683 de 2015, la Corte Constitucional estableció que las parejas del mismo sexo pueden aplicar al proceso de adopción, siguiendo los parámetros establecidos en la normatividad que regula el tema, con fundamento en el interés superior del menor. Sobre esta situación véase De Felice (2016).

3 Prueba de ello fue que en el Anuario Pontificio 2017 y de Estadísticas de la Iglesia 2015 que dio a conocer el Vaticano, Colombia se ubica como el sexto país con mayor número de católicos en el mundo, con un total de 45,3 millones, superando a países como España o Argentina (Redacción Vida, 2017). Adicionalmente, muchos movimientos e iglesias cristianas aprobaron la propuesta de la senadora Morales, sobre esto véase el artículo: La carta de los cristianos al Congreso (2017).
} 
Estos pensamientos encuentran su fundamento en la "prohibición de atar a sus hijos", formulada por el filósofo inglés John Locke, en los siguientes términos: "cualquier compromiso o promesa que alguien haya hecho por sí mismo, está bajo la obligación de éste, pero no puede por ningún pacto que sea, atar a sus hijos a la posteridad" (Locke, 1988, p. 346).

En este orden de ideas, existe una tensión entre democracia y constitucionalismo, puesto que para algunos constitucionalistas la primera es un peligro, mientras que para algunos demócratas el segundo es un fastidio (Holmes, 1999). Esta situación, materializada en el ejemplo reseñado inicialmente, lleva a plantear algunos interrogantes. Entre ellos, y teniendo en cuenta que la participación democrática constituye un derecho político de rango fundamental, se podría preguntar: ¿cualquier interés democrático es vinculante?, es decir, ¿cualquier interés democrático debe producir consecuencias jurídicas y políticas?

Para dar respuesta a esto, en el presente texto se tratarán los siguientes tópicos: en primera medida, se abordarán la postura democrática y sus implicaciones; luego, se profundizará en la postura constitucionalista y en los elementos que hacen parte de ella; finalmente, se propondrá la figura del constitucionalismo democrático como solución a esta dicotomía.

No sobra advertir que esta problemática no es propia de ninguna disciplina, por lo que el presente trabajo marca un punto de intersección entre la Filosofía Política, la Filosofía Jurídica, el Derecho Constitucional y la Teoría del Derecho.

\section{Metodología}

El método investigativo que se emplea en el presente trabajo es de tipo dialéctico, puesto que se contrastan posiciones. En primer lugar se presenta una tesis, que es la postura democrática; luego se aborda su antítesis, que es el constitucionalismo; finalmente se propone una síntesis a este problema, que es el constitucionalismo democrático.

\section{Postura democrática}

La postura democrática, como se enunció anteriormente, encuentra su fundamento en el principio de "prohibición de atar a sus hijos", formulado por Locke (1988). Esta concepción es entendida como una forma de gobierno en la que el 
poder es ejercido por los representantes que son escogidos por la mayoría ${ }^{4}$. En este sentido, las decisiones adoptadas por ellos son la manifestación del pueblo (Ferrajoli, 2016). En palabras de Abraham Lincoln (1863) $)^{5}$, "un gobierno del pueblo, por el pueblo y para el pueblo".

Dicha idea, en su acepción formal ${ }^{6}$, rechaza el precompromiso constitucional, debido a que este instituye límites a los legisladores, lo cual va en contravía de la idea de soberanía popular. Lo anterior, en la medida en que esta no pertenece a nadie más que al pueblo (Ferrajoli, 2009) y al establecerse límites en contra de la manifestación popular se estaría ante la presencia de la usurpación de dicha soberanía.

Por lo anterior, esta visión democrática encuentra su desarrollo en posiciones como las de Thomas Paine y Thomas Jefferson. Para Paine (1995), cada generación, así como la que le precedió, debe tener libertad para decidir sobre los asuntos que se le presenten, porque los muertos no deben determinar a los vivos. Así pues, cuando una persona muere, ya no cuenta con autoridad para indicar cómo debe organizarse o administrarse el gobierno.

En ese mismo sentido, la idea de precompromiso constitucional debe tener legitimidad solo para la generación que la adopta y no para las siguientes. Así, "la generación actual tiene el derecho ilimitado e ilimitable de remodelar las instituciones bajo las cuales vive. El único consentimiento que legitima cualquier forma de gobierno es el consentimiento de los vivos" (Holmes, 1999, p. 224).

Bajo la visión de Paine, y el carácter temporal del precompromiso, sería coherente y consecuente que, en un determinado territorio $\mathrm{X}$, en el que una generación anterior haya decidido abolir la pena de muerte y una generación presente la instaure nuevamente, fuese posible que una generación futura pudiese abolirla.

En cambio, sucede algo que resulta de cierta manera contradictorio con la noción de Jefferson, teniendo en cuenta que para él, como resalta Holmes (1999),

\footnotetext{
4 No sobra mencionar que existen sistemas de elección proporcional, en los cuales la mayoría de los gobernantes pertenecen a la mayoría de electores y la minoría de representantes corresponden a la minoría de electores. Esta figura encuentra su fundamento en la obra del filósofo y economista inglés John Stuart Mill (1878).

5 Esta frase fue pronunciada durante el discurso que brindó Abraham Lincoln en la ciudad de Gettysburg (Pensilvania), en el marco de la Guerra Civil estadounidense.

6 La democracia formal tiene que ver "con el quién (el pueblo o sus representantes) y el cómo (la regla de la mayoría) de las decisiones, pero sería independiente de qué se decide, es decir, de los contenidos, aunque éstos fueran antiliberales, antisociales e incluso antidemocráticos" (Ferrajoli, 2009, p. 75).
} 
las constituciones imponen límites sobre los legisladores, lo que imposibilita la negación de libertades consagradas en la declaración de derechos. Empero, al mismo tiempo, considera que los pueblos son señores y amos de sí mismos, que pueden gobernarse como les plazca y que, a casusa de esto, tanto la Constitución como las leyes tienen un carácter temporal, mas no perpetuo, considerando que la muerte física de los redactores de la primera trae consigo su muerte espiritual ${ }^{7}$ (Jefferson, 2004).

Atendiendo esta perspectiva, los límites bajo los cuales se ciñe el legislador son los que se le han dado durante su tiempo y no los impuestos por legisladores del pasado. Por ejemplo, bajo esta visión:

- Los constituyentes del país K, en el año 0010, establecen como uno de los principios rectores de su constitución el respeto por la libertad y la prohibición de la esclavitud.

- En el año 0012, debido a cambios políticos, se piensa modificar la Constitución, de tal manera que se permita la esclavitud.

- Debido a que la Constitución del 0010 indica que el respeto a la libertad es uno de sus principios rectores, la reforma a la misma no procede y, por lo tanto, no se revive la figura de la esclavitud.

- Sin embargo, trascurridos cien años, es decir, en el 0102, se vuelve a presentar la misma propuesta de reforma.

- Para esta fecha, los redactores ya están fallecidos y, con esto, el espíritu de la Constitución misma, por lo que es procedente la reforma. Así, se revive la esclavitud, debido a que los legisladores del pasado no pueden imponer límites a los actuales.

Actualmente, gracias al profesor norteamericano Jeremy Waldron ${ }^{8}$, las posiciones de Jefferson y Paine, pese a ser de los siglos XVII y XVIII ${ }^{9}$, están teniendo

7 La crítica del carácter permanente de las Constituciones, que formula Jefferson, se debe a que la idea de que algo sea o pueda ser perpetuo es moralmente aborrecible, debido a que, al tiempo, se continúan servidumbres y monopolios (Holmes, 1999).

8 En la actualidad, según reseña Cristina Foroni (2015), Waldron se ha convertido en un referente en la Teoría y
Filosofía del Derecho, más específicamente en los problemas que se desprenden de la relación entre la democracia
y los derechos fundamentales, debido a que centra la atención en las prácticas democráticas, mas no en la protec-
ción y aplicabilidad de dichos derechos.

9 A pesar de esto, ha tenido una constante aplicación durante los siglos Xx y XXI. Ejemplo de esto es la iniciativa de la senadora Morales, mencionada en la introducción de este escrito. 
-teóricamente hablando- una gran acogida. Para este autor, según indica Santiago Virgüez (2015), las decisiones políticas fundamentales deben ser adoptadas por la mayoría mediante mecanismos de votación, lo que constituye una concepción democrática coherente con la idea de la premisa mayoritaria.

$\mathrm{Su}$ fundamentación radica en que, primero, cuando se adopta una decisión aprobada por la mayoría, se genera que este punto de vista predomine con "fuerza vinculante", inclusive sobre personas que no lo compartan; segundo, en que el proceso de mayorías tiene un carácter neutral, debido a que posibilita la interacción y participación directa de todos los miembros de una comunidad, o de toda la ciudadanía, ya que cada opinión tiene el mismo valor, esto es, una persona, igual un voto (Virgüez, 2015).

Lo anterior se condensa en la siguiente figura:

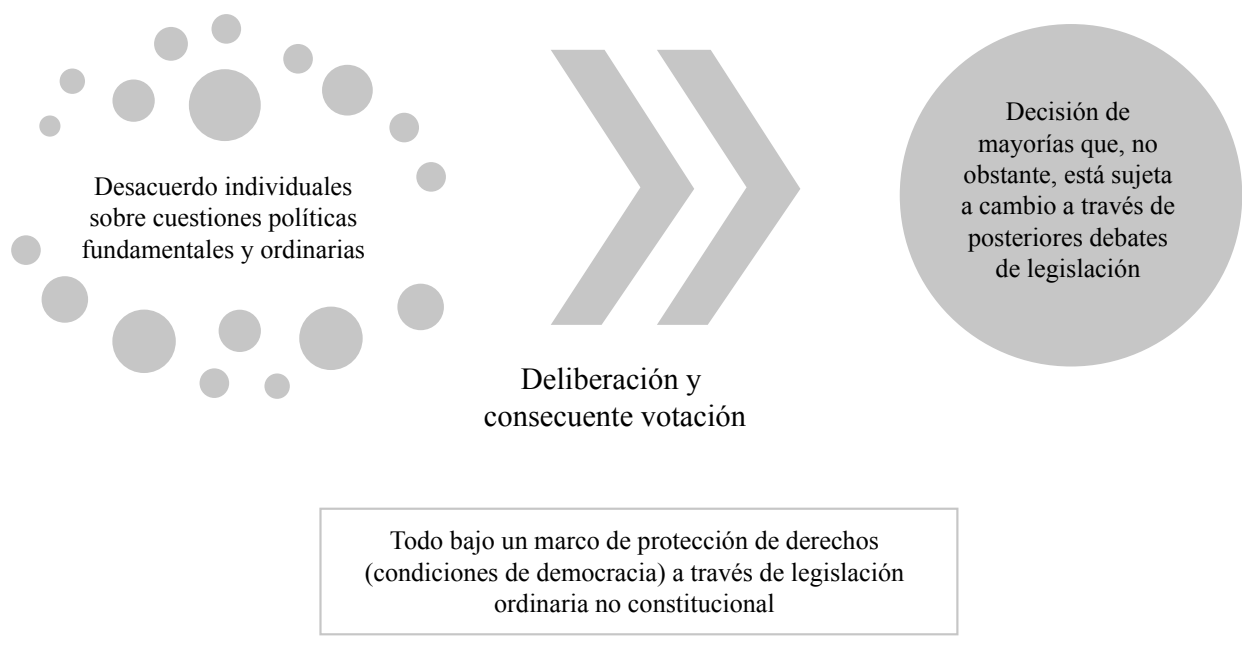

Figura 1. Tomada de Democracia, desacuerdo y derecho constitucional. Una revisión a la tensión entre constitucionalismo y democracia en el debate Dworkin - Waldron (Virgüez, 2015, p. 13).

En este sentido, la posición de Waldron está fundada en la idea de deliberación $^{10}$, que está en manos del legislativo, cuya finalidad principal no es lograr

10 La democracia deliberativa encuentra como representante en Europa a Jurgen Habermas (2005), en Norteamérica a John Rawls (2006), en Latinoamérica a Roberto Gargarella (2006) y en Colombia a Oscar Mejía Quintana (1998). Esta forma de entender la democracia se sustenta en la teoría del discurso habermasiano, la cual 
un consenso, sino que, por el contrario, tiene que ver con sentar las bases del desacuerdo (Virgüez, 2015), las cuales abarcan los cuestionamientos sobre qué se está discutiendo, por qué se discute y hacia dónde va la discusión. Dicho en otras palabras, cuando se habla de deliberación, casi siempre se tiene la creencia de que esta lleva al consenso, pero cuando existen diversas opiniones (circunstancias de disenso) puede que lo que acarree sea todo lo contrario, es decir, el desacuerdo (Waldron, 2004).

Después de sentar las bases del disenso, se procede a una deliberación democrática sobre lo ya desacordado (figura 1), en la que se expresan argumentos sobre las distintas posiciones y visiones que hacen parte del mismo, para finalmente obtener una decisión mayoritaria, que no es definitiva, debido a que en futuros debates puede sufrir modificaciones (Waldron, 2005).

De esta forma, la noción de Waldron encaja en una de carácter procedimental, más específicamente dentro del denominado procedimentalismo débil (Linares, 2008). Esto tiene las siguientes implicaciones:

1. La decisión política fundamental debe ser tomada por un órgano facultado para ello, esto es, por el Congreso (Virgüez, 2015).

2. La importancia reside en el hecho de que las personas tengan manera de intervenir, ya que la participación, en términos del autor, constituye "el derecho de derechos" (Waldron, 2005, p. 337) ${ }^{11}$.

toma como referente dos visiones: la liberal y la republicana (Mejía, 1996). Dichas ideas fueron planteadas por Rawls en el liberalismo político (2011), las cuales, a su vez, recientemente tuvieron una revisión teórica por parte de Marta Nussbaum (2014). En este sentido, la teoría discursiva

asume elementos de ambas concepciones y los integra en el concepto de un procedimiento ideal para la deliberación y la toma de resoluciones. Pues el procedimiento va a generar una conexión interna entre negociaciones, discursos de autocomprensión y discursos referentes a la justicia, convencida de que, en tales condiciones pueden alcanzarse resultados racionales y equitativos. La autocomprensión normativa de la política deliberativa exige de la comunidad jurídica un modo discursivo de socialización (Mejía, 2008, p. 165).

Además, no sobra agregar que Habermas, según señala Domínguez (2013), menciona cuatro elementos constitutivos sin los que no es posible hablar de democracia deliberativa. Estos son: ciudadanía y opinión pública; esfera pública; participación; y deliberación pública.

11 Sobre este punto, el mismo Waldron (1993) señala:

\footnotetext{
Al final, creo, el asunto se reduce a esto. Si un proceso es democrático y se obtiene el resultado correcto, no es injusto para nadie. Pero si el proceso no es democrático, se produce una injusticia de manera inherente y necesaria al efectuarlo, en su funcionamiento, a las aspiraciones participativas del ciudadano común. Y se produce esta injusticia, se tiraniza de este modo, se alcance o no el resultado correcto (p. 50).
} 
3. La constitucionalización de determinados tipos o clases de derechos impone una inmunidad sobre los mismos, es decir, que estos no pueden ser modificados. No obstante, lo que caracteriza a la democracia es el disenso, por lo que, a su juicio, no habría razón para darle prevalencia o especial protección a cierto tipo de derechos (Virgüez, 2015). En esa medida, dicha inmunidad iría en contravía de la democracia misma. Adicionalmente, parafraseando a Waldron (1993), si a los individuos se les atribuyen determinados derechos que están fuera de la órbita de discusión, ya que cuentan con cierta inmunidad, es porque se parte de una desconfianza que es contradictoria con la autonomía que cimienta el hecho de reconocerle derechos a un sujeto ${ }^{12}$.

4. La Constitución debe ser diseñada de tal manera que posea un carácter diverso (Waldron, 2005), esto es, que en ella se reflejen posturas contradictorias entre sí, tanto las de índole progresista como las de índole conservadora.

Dicho lo anterior, cabe añadir que Waldron en ningún momento menciona o hace alusión a que el poder o la voluntad democrática deban tener algún tipo de límite. Es más, critica instrumentos como el coto vedado, el cual se puede entender como "el conjunto de principios y/o reglas básicas de rango constitucional que ningún poder político constituido, ni siquiera aquél de la mayoría en los Estados democráticos de derecho, puede violar" (Bovero, 2008, p. 218).

Las críticas de Waldron a este instrumento, según menciona Moreso (2009), son dos. Por una parte, que si al coto vedado se le escapa algún derecho que no esté reconocido en la Carta Magna, se debe o hacer una reforma constitucional para que se incluya en ella o hacer un reconocimiento del mismo por vía interpretativa, a través de una sentencia emitida por el Tribunal Constitucional. Por otra, al no haber una claridad conceptual sobre qué derechos hacen parte del coto

\footnotetext{
12 Esto refleja que la postura de Waldron rechaza la incorporación de las llamadas cláusulas pétreas de la Constitución, cuya función es la de garantizar la inmodificabilidad de determinados postulados constitucionales, como son, en algunos casos, los derechos fundamentales o los principios fundantes básicos de la Carta Política. Dichas cláusulas, para algunos académicos, deben estar de forma explícita en la Constitución, mientras que para otros pueden estar de forma implícita. Sobre esto, véase: Sentencia C-288 de 2012, proferida por la Corte Constitucional colombiana, Gómez (2012) y Cajas (2004).
} 
vedado $^{13} \mathrm{y}$, más aún, sobre el significado de los mismos, se pueden presentar situaciones paradójicas, como que la libertad de expresión incorpore el ver pornografía ${ }^{14}$, los insultos u ofensas raciales o incendiar la bandera nacional.

En consonancia con esto, hay que mencionar, además, que otro de los principales aportes de Waldron, el cual tiene una relación estrecha con su forma de entender la democracia, es la crítica que formula al control de constitucionali$\mathrm{dad}^{15}$ ejercido por los jueces ${ }^{16}$. Para este autor, aquellos carecen tanto de autoridad como de legitimidad democrática ${ }^{17}$ para limitar la voluntad del legislador. En este sentido, expone que al declarar la inexequibilidad de una norma, esto es, expulsarla de un ordenamiento jurídico determinado porque va en contravía de un precepto de carácter constitucional, el juez se está extralimitando en sus funciones, puesto que la labor de crear el derecho le compete solamente al legislador en representación del pueblo (Waldron, 2015). De esta forma, el control de constitucionalidad no debería estar en manos del poder judicial, sino en cabeza del legislativo, debido a su autoridad y legitimidad democrática, mediante la aplicación de la figura del control de constitucionalidad de la legislación ${ }^{18}$.

En suma, la postura democrática va a enfatizar en la vinculatoriedad de cualquier interés político, en razón de la libertad que tiene el pueblo para determinarse así mismo, en la ausencia de precompromisos y en la falta de legitimidad que

13 Ernesto Garzón Valdés (1989) estima que los derechos que están dentro del coto vedado son aquellos que están relacionados con la satisfacción de bienes básicos, es decir, con los elementos necesarios para la ejecución de un plan de vida.

14 Sobre la discusión entre libertad de expresión y pornografía, véase Mackinnon \& Posner (1997).

15 En Latinoamérica, la critica a esta figura ha sido realizada por Roberto Gargarella (2011), como se muestra en el caso Marbury vs Madison, con el cual nace la figura de control de constitucionalidad. Sobre este veáse Marbury vs Madison, 1803, Ponente John Marshall (2006). El origen de esta figura es conservador y elitista, obviando que, en cuestiones que afecten a los ciudadanos, debe existir una mayor deliberación.

16 Esta cuestión fue objeto del debate entre Hans Kelsen y Carl Schmitt, el cual es considerado uno de los más importantes de la teoría jurídica constitucional del siglo xx. Dicho debate se podría sintetizar de la siguiente forma: mientras que, por un lado, para Schmitt (véase Schmitt, 2004; Schmitt, 1996; Schmitt, 2009) el guardián de la Constitución debe ser el Jefe de Estado (el Führer), debido a que este cuenta con la legitimidad para ello, ya que representa el querer del pueblo; por el otro lado, para Kelsen (véase Kelsen, 1995, Kelsen, 2009 y Kelsen, 2001) la función de guardián y protector de la Constitución le corresponde no al Jefe de Estado, ni tampoco al Parlamento, sino que le compete a los Tribunales Constitucionales, debido a la garantía jurisdiccional de los mismos.

17 Otro argumento del porqué los jueces carecen de autoridad democrática es que estos no son elegidos democráticamente, como sí lo es el legislador. Sobre esto véase Gargarella (1997). Igualmente, también se les reprocha a los jueces que, a diferencia del legislador, no tengan un acercamiento con la ciudadanía (Gargarella, 2015) y que las soluciones que aportan se hacen netamente desde el punto de observadores.

18 Para analizar una defensa de la misma, diferente a la presentada por Waldron, véase Harel \& Kahana (2015). 
tienen los Tribunales Constitucionales para declarar la inconstitucionalidad ${ }^{19}$ de una norma promulgada de manera democrática, puesto que su función no es esa, sino la de aplicar el Derecho.

\section{Postura constitucionalista}

La visión constitucionalista toma como referente los problemas e inconvenientes que genera la concepción democrática formal, entre ellos, que la idea democrática pueda asemejarse a un caballo desbocado, por lo que esta necesitaría límites, tales como la Constitución (Holmes, 1999). Si el pueblo no tiene ningún límite puede caer en situaciones antidemocráticas, por ejemplo, en el establecimiento de regímenes dictatoriales ${ }^{20}$.

Otro problema es que la situación reseñada previamente conlleva la manifestación de la denominada paradoja de la democracia. Esta es expresada por Jon Elster (2000) en los siguientes términos: "Cada generación desea ser tan libre para obligar a sus sucesores, sin estar obligada por sus predecesoras" (p. 115). Por el contrario, perspectivas como la de Holmes (1999) estiman que no existe una paradoja entre democracia y Constitución, sino una incoherencia, debido a que lo que un pueblo ha decidido libremente otorgarse no puede ser arrebatado por él mismo.

Los inconvenientes enunciados acarrean una solución por parte del constitucionalismo $^{21}$, que es la defensa del precompromiso ${ }^{22}$. Esta garantía tiene su fundamento en la racionalidad imperfecta, formulada por Jon Elster (2000), quien la

19 En palabras de Jeremy Waldron (2018),

la democracia es una forma de gobierno que trata de resolver desacuerdos y que empodera a cada persona por igual, dado que reconoce que cada uno tiene una dignidad para expresar su opinión sobre una decisión política. Y el control judicial es una forma de bloquear ese empoderamiento: es una forma de delegar la toma de decisiones a ciertas personas con fundamento en criterios pretendidamente objetivos, como los de ser más listos o los mejores, en lugar de confiarlo a gente del común (p. 173).

20 Téngase en cuenta que muchas dictaduras han subido al poder de forma democrática, como la nazi en Alemania. Sobre esto, véase Lozano (2008).

21 Estimaciones constitucionalistas, como las de Ronald Dworkin (2014), enfatizan en el hecho de que

\footnotetext{
la Constitución, y particularmente la Bill of Rights, está diseñada para proteger a los ciudadanos individuales y a los grupos en contra de ciertas decisiones que una mayoría de ciudadanos pudieran querer tomar, incluso cuando la mayoría actúa en lo que se tiene como interés general o común (p. 211).
}

22 Los precompromisos constitucionales establecen límites a las discusiones e incluso a la misma soberanía parlamentaria (Moreso, 2009). 
ejemplifica haciendo alusión al mito de Ulises y las sirenas, que está contenido en La Odisea de Homero (2006).

Según esta historia, toda embarcación que cruzaba cerca de las sirenas se estrellaba con la costa, debido a que ellas hipnotizaban con su canto a los tripulantes de los barcos. Ulises, al saber esta situación, fue consciente de que no podría evitar caer bajo el encanto de las sirenas, así que decidió amarrarse al mástil de su barco para evitar tal situación.

En el ejemplo de la Odisea se está ante una racionalidad imperfecta, debido a que, para evitar chocar contra la costa, Ulises decide amarrase contra el mástil de su barco. Se estaría ante una racionalidad perfecta si el personaje no hubiese tenido que realizar tal acción (Moreso, 1997). Por ello, el precompromiso es una especie de racionalidad imperfecta, ya que una soberanía absoluta, que no tenga ningún tipo de límites, puede acarrear situaciones totalmente antidemocráticas, como la vulneración de derechos (Ferrajoli, 2006).

La justificación del precompromiso reside en los siguientes postulados:

Una generación anterior no puede impedir que la generación ulterior diga: ¡No queremos más libertad! Pero esta incapacidad no implica que los predecesores no tengan derecho o razón para formar unas instituciones pensando en dificultar semejantes decisiones. Cuando intentan atar el futuro, los constitucionalistas no solo están tratando de ejercer dominación y control. El pre-compromiso se justifica porque, en lugar de simplemente quitar opciones, pone a su disposición ciertas posibilidades ${ }^{23}$ que de otra manera quedarían fuera de todo alcance (Holmes, 1999, p. 247).

Dicho en otros términos, una generación anterior, en principio, no debe obligar a una generación futura. No obstante, existe una excepción a este postulado, que expresa: sí es posible obligar a una generación futura, siempre y cuando haya adquirido un derecho de la generación anterior ${ }^{24}$ (Holmes, 1999). Por consiguiente, se ataca el principio de no atar a los hijos por medio del carácter vinculatorio del precompromiso ${ }^{25}$, debido a que vivos y muertos están constituidos por

23 Generalmente, "los individuos tienden a perder poder y libertad cada vez que por sí solos intentan resolver todos sus problemas. Al aceptar una Constitución prestablecida, un pueblo se ata sus propias manos, pero también se libera de cargas considerables" (Holmes, 1999, p. 244).

24 Esta idea también se desarrolla en la Filosofía Política, debido a que, "para alcanzar sus objetivos, los miembros de una sociedad política deben aceptar disipaciones legales que aten a sus voluntades" (Holmes, 1999, p. 257).

25 Dos ejemplos de vida cotidiana en los que se materializan los precompromisos, podrían ser: primero, una persona que generalmente ignora su alarma despertadora, coloca el dispositivo del que hace parte a determinada 
un mismo pueblo. Ejemplo de esto podría ser una norma aprobada cuando una persona tiene veinte años y que sigue vigente cuando la persona tiene cincuenta (Holmes, 1999).

Ahora bien, los precompromisos, según apunta Holmes (1999), a pesar de tener un carácter protector respecto a las minorías, son democráticos y mayoritarios $^{26}$, por lo que las Constituciones liberales poseen metalimitaciones, las cuales son "reglas que obligan a cada mayoría a exponer a la crítica y a una posible revisión sus decisiones; reglas que limitan la capacidad de cada generación de borrar opciones significativas a sus sucesores" (Holmes, 1999, p. 248).

Al fijar límites a las discusiones políticas, esto es, al sacar de la órbita de discusión legislativa determinados derechos, los precompromisos operan como una restricción autoimpuesta, garantizando los valores fundamentales de las prácticas democráticas (Foroni, 2015) como la igualdad. Todavía cabe señalar que estos, al ser un instrumento, propenden por "asegurar decisiones acertadas en la medida en que lo que el mecanismo protege es algo digno de protegerse. Ello ocurre tanto en las decisiones individuales como en las decisiones colectivas" (Moreso, 1998, p. 97).

Vale la pena aclarar que los precompromisos, según asevera Moreso (1998), pueden asegurar determinadas situaciones, que no son del todo loables. Dos ejemplos de ello son: primero, una persona que ordena a su banco que le debiten mensualmente determinado porcentaje de su cuenta de ahorros, con la finalidad de comprar bebidas alcohólicas que consumirá, sin compañía, noche a noche; segundo, el establecimiento, en la Constitución Política, de la pena de muerte como un mecanismo de precompromiso que no puede ser modificado por generaciones futuras.

Estos dos casos demuestran que el precompromiso constitucional no garantiza que la decisión que está dentro del mismo sea "digna" de protegerse. Para que adquiera tal calificación, este debe responder a un concepto de justicia ${ }^{27}$ y ser

\footnotetext{
distancia y a un volumen elevado, lo que acarrea que, para poder apagarla, deba ponerse de pie; segundo, las leyes que impiden que las personas voluntariamente consientan trabajar por menos del salario mínimo legal mensual vigente (Foroni, 2015).

26 Los derechos, "no fueron planteados tan solo para la protección de la minoría, sino también para la corrección y la instrucción de la mayoría" (Holmes, 1999, pp. 255-256).

27 Moreso (2009) menciona en su obra un concepto de justicia rawlsiano. Sin embargo, debe aclarase que existen una gran variedad de conceptos de justicia, entre los que están: el de Rawls (2006), desde la Filosofía del Derecho
} 
coherente dentro del sistema jurídico en el que se enmarca. Asimismo, debe responder a los principios y valores propios de dicho sistema, generando garantías para los ciudadanos.

En síntesis, el constitucionalismo -en su sentido clásico-, impone límites a la democracia para evitar caer en su régimen dictatorial y antidemocrático. Igualmente, propende por un defensa del precompromiso, en cuanto a los derechos reconocidos por medio de la Carta Política o de sus posteriores reformas y enmiendas.

Así, no todos los intereses políticos tienen un carácter vinculante y no deben producir consecuencias políticas ni jurídicas, debido a que encuentran un límite en los derechos preestablecidos y en la Constitución misma. No obstante, esta situación genera la sensación de que la Carta Política anula el querer democrático, toda vez que no existe un criterio objetivo para determinar cuándo una decisión democrática atenta o va en contravía de principios constitucionales. Esto se materializa principalmente en el momento en que el operador judicial realiza el control de constitucionalidad de las normas jurídicas.

Esta situación es uno de los reflejos de la tensión existente entre democracia y constitucionalismo. Por ejemplo, téngase en cuenta el caso de la reelección presidencial en Colombia. En un primer pronunciamiento de la Corte Constitucional, mediante la Sentencia C-1040 de 2005, se avaló la primera reelección del entonces presidente Álvaro Uribe Vélez. Este logró su cometido gracias a que en las elecciones presidenciales del 2006 obtuvo 7,397.835 votos, lo que se traduce en un $62.35 \%$ de la votación total.

No obstante, en el año 2010, por medio de la Sentencia C-141, la Corte declaró inexequible la Ley 1534, por medio de la cual se convocaba a un referendo, con la finalidad de decidir acerca de una reforma constitucional, que buscaba darle vía libre a una segunda reelección presidencial. Tal decisión fue fuertemente criticada por los defensores de las posturas democráticas, porque, desde su punto de vista, tal decisión atentaba contra el querer democrático. Téngase en

y la Filosofía Política; el de Dworkin (2012), desde la Filosofía del Derecho y la Teoría del Derecho; y el de Alexy (2008a), desde la Teoría del Derecho; entre otros. 
cuenta que si se hubiera dado tal modificación constitucional, lo más seguro es que Álvaro Uribe hubiese logrado su segunda reelección ${ }^{28}$.

Otra crítica que se le hizo a la Corte Constitucional fue sobre su falta de coherencia frente a la argumentación que empleó en las dos sentencias ${ }^{29}$. No obstante, más allá de dichas críticas, la primera reelección, que contó con un gran apoyo de los votantes, logró un desequilibrio en la tridivisión de poderes -principio fundante del Estado Social de Derecho colombiano-, y acarreó un daño al sistema jurídico y político, razón por la que, en el 2015, se eliminó tal figura mediante acto legislativo 02 .

Este ejemplo conlleva afirmar que no siempre las decisiones mayoritarias deben producir consecuencias políticas y jurídicas, puesto que estas (como el caso de la reelección en Colombia) ponen en peligro a la democracia misma, dado que su fundamentación reside en intereses democráticamente viciados. Lo anterior, considerando que uno de los elementos fundantes ${ }^{30}$ de la democracia es la alternancia del poder (Frápolli, 2012).

A pesar de ello, no se deben anular las decisiones que no tienen intereses democráticos viciados, porque si se ata muy fuerte a Ulises, este se puede asfixiar (Benítez, 2012). Es decir, en aras de garantizar la Constitución y, a su vez, los precompromisos constitucionales, no se pueden anular las decisiones democráticas tomadas de forma racional. Por lo tanto, es necesario determinar los criterios que permitan establecer cuándo un interés democrático está viciado, es decir, es irracional, y cuándo no. Al mismo tiempo, debe dilucidarse en qué momento dicha decisión va en contravía de los principios constitucionales y afecta los derechos fundamentales. De esa forma, es posible lograr una reconciliación entre Constitución y democracia.

28 Sobre esto, véase el artículo: Corte Constitucional le dijo no a la segunda reelección del presidente Álvaro Uribe (2010).

29 Al respecto, véase: Bernal (2013).

30 En lo concerniente a los elementos estructurales de la consolidación democrática, véase Gasiorowski \& Power (1998). 


\section{Constitucionalismo democrático como solución alternativa a la tensión entre democracia y constitucionalismo}

Hasta este momento, en lo que se ha desarrollado del texto, parece que la tensión entre democracia y constitucionalismo no puede reconciliarse. Por un lado, se estima que la voluntad del pueblo no debe tener ningún tipo de límites y/o ataduras, por ello, cualquier interés democrático es vinculante y produce consecuencias tanto políticas como jurídicas.

Por otro, existen límites - que residen en la Constitución- a la voluntad popular, lo que conlleva aseverar que no todos los intereses democráticos son vinculantes, especialmente los que blindan y protegen derechos. Sin embargo, el constitucionalismo clásico no determina el rasero para establecer la calificación de los intereses democráticos y, por lo tanto, si estos deben, o no, producir consecuencias jurídicas.

Ante esta situación, al parecer irreconciliable, el constitucionalismo democrático $^{31}$ o moderno ${ }^{32}$ se sitúa como punto intermedio en esta dicotomía, puesto que para que exista democracia es necesario que haya una Constitución que proteja los derechos fundamentales. De igual manera, la función de la Carta es demarcar, por lo menos de manera genérica, cómo se deben tomar las decisiones democráticas, dado que ella es un prerrequisito de la democracia (Nino, 2013). Así, y de acuerdo con Luigi Ferrajoli (2009),

la novedad que el constitucionalismo introduce en la estructura de las democracias es que también el supremo poder legislativo se encuentra jurídicamente regulado y limitado, no sólo en lo que respecta a las formas, que garantizan la afirmación de la voluntad de la mayoría, sino también a la sustancia de su ejercicio, vinculado al respeto de normas constitucionales específicas, como el principio de igualdad y los derechos fundamentales (p. 77).

31 Rawls (2011) le ha dado la connotación de carácter dualista, puesto que hace una diferenciación entre el poder constituyente -poder supremo del pueblo- y el ordinario -poder del Parlamento-. Además, resalta que la supremacía parlamentaria es rechazada.

32 Los orígenes del constitucionalismo moderno se encuentran en las obras y aportaciones de autores como Hobbes, Rousseau, Montesquieu y Stuart Mill. A partir de ellas se hallan y abordan diversos problemas, como: a) la relación entre legitimidad y consentimiento; b) los problemas en torno a la relación del Derecho con la política; c) las cuestiones en torno a la voluntad del individuo, su relación con el Estado y la razón; d) lo ateniente a la libertad y diversidad (Bonilla, 2013). 
Bajo esta perspectiva, el constitucionalismo democrático blinda tanto a la Constitución ${ }^{33}$-a través de la rigidez constitucional- como a la democracia mis$\mathrm{ma}^{34}$, evitando que esta última caiga en regímenes dictatoriales o en situaciones anárquicas (Calsamiglia, 1999) ${ }^{35}$. Lo anterior, a partir de determinados límites, como el respeto a las normas constitucionales de carácter específico, a los principios fundantes del Estado - contenidos dentro de la Constitución- y a los derechos fundamentales ${ }^{36}$.

En este sentido, las limitaciones no son una debilidad, sino todo lo contrario, robustecen la democracia (Holmes, 1999). Por lo tanto, las decisiones del presente pueden ser tomadas con base en precompromisos ya existentes, lo que acarrea un replanteamiento del concepto clásico de la misma (Agudelo \& Prieto, 2016).

Con base en lo anterior, los precompromisos, además de ser un límite, también son directrices (Dworkin, 2014), ya que marcan el punto a seguir en las discusiones políticas actuales. En este sentido, en una sociedad ya no sería necesario debatir si el derecho a la vida es inviolable o no, dado que este ya estaría por fuera de la discusión parlamentaria; por lo contrario, esta se haría sobre cómo darle una mayor garantía al mismo, mejorando la discusión legislativa.

Por otro lado, como se señaló previamente, la rigidez constitucional, que no es una garantía sino un rasgo estructural, (Ferrajoli, 2009), robustece tanto a la Constitución como a la democracia. La Carta Política se entiende rígida cuando "el procedimiento de reforma a esta es más complejo que el procedimiento

33 Bajo esta visión, la Constitución se convierte en un límite, controlando el poder y evitando la generación o manifestación de absolutismos, puesto que estos van en contra de los derechos (Martínez, 2014).

34 Un pueblo

puede decidir, "democrática" y contingentemente, ignorar o destruir la propia constitución y entregarse definitivamente a un gobierno autoritario. Pero no puede hacerlo de forma constitucional, invocando a su favor el respeto de los derechos de las generaciones futuras o la omnipotencia de la mayoría, sin suprimir con ello el método democrático, los derechos y el poder de las mayorías y de las generaciones futuras (Ferrajoli, 2009, p. 96).

35 En palabras de Ferrajoli (2009),

precisamente para salvar esta contradicción y para garantizar la democracia, se desarrolló el constitucionalismo del siglo veinte tras las experiencias de los fascismos que, mediante formas políticamente democráticas, habían conquistado el poder primero, y destruido la democracia después. De aquí el nexo estructural entre democracia y constitucionalismo (p. 85).

36 Téngase en cuenta que existen ciertas disposiciones que tienen un carácter bivalente, e incluso plurivalente. Por ejemplo, la igualdad tiene un carácter de principio, valor y derecho. Al respecto, véase Corte Constitucional colombiana, Sentencia C-1287 de 2001. 
legislativo ordinario" (Agudelo, 2012, p. 158). Esto conforma límites de tipo conceptual o lógico y límites formales.

Por una parte, los límites lógicos no proceden del contenido de las disposiciones constitucionales, sino del concepto de Constitución adoptado. Por otra, los formales hacen referencia a las exigencias de carácter específico que tienen por objetivo la validez de la reforma (Pulido, 2017).

Ello implica que la Constitución no establece una prohibición de reforma ${ }^{37}$, sino que, por lo contrario, la permite siempre y cuando el proceso de esta sea más complejo que los demás procedimientos legislativos (límites formales). Además, existe una imposibilidad para hacer que dichos medios de reforma se flexibilicen de tal manera que su trámite sea igual al de una ley ordinaria (límites conceptuales o lógicos) (Pulido, 2017).

Esta figura se relaciona con el carácter superior de las normas constitucionales sobre las demás fuentes del ordenamiento jurídico, debido a que estas cumplen expectativas negativas en relación a la no derogación de derechos fundamentales, y positivas en relación al desarrollo y alcance de dichos derechos (Ferrajoli, 2009).

Hasta ahora se ha abordado la rigidez como una característica de la democracia constitucional, por lo que, a continuación, se analiza un elemento que va de la mano de esta y que es la no limitabilidad de los derechos fundamentales. Estos tienen diversas definiciones ${ }^{38}$, sin embargo, para efectos prácticos, se acude a la que es brindada por el jurista alemán Martin Brodowski (2015).

Para el autor, los derechos fundamentales poseen siete características $^{39}$ : tienen una consagración en el derecho positivo; son el resultado de la incorporación jurídica de los derechos humanos a los sistemas jurídicos nacionales; tienen un

37 La imposibilidad de reforma de la Constitución, sea bien de manera total o solo a disposiciones determinadas, hace referencia a un límite de carácter material (Pulido, 2017). Cuando esta considera solo partes en específico, se está ante la presencia de las denominadas cláusulas pétreas de la Constitución. Sobre estas, véase Sant'Ana Pedra (2010).

38 Algunas posturas teóricas estiman que los derechos fundamentales son el resultado de la positivización de los derechos humanos, ya que los primeros, en términos prácticos, tienen una mayor exigibilidad que los segundos (Agudelo \& Riaño, 2016).

39 Cada una de estas siete características constituye un problema de investigación autónomo, sobre los que existe una vasta bibliografía. Al respecto, véase: Peces-Barba (1995), Loewenstein (1937), Alexy (2009), Ferrajoli (2001), Alexy (2008b), Arango (2012), De Sousa Santos (1998), Brodowski (2003), Alexy (2003), Bernal (2014), Fioravanti (2009) y Williams (2003). 
carácter individual; se poseen como una garantía de los sujetos de derechos frente al Estado; tienen un carácter abstracto; poseen un contenido sustancial; y ostentan una preponderancia dentro del ordenamiento jurídico.

A partir de estas siete características, se determina que los derechos fundamentales constituyen un límite a la voluntad popular, debido a que se poseen frente al Estado, tienen un carácter individual y no son irrenunciables ${ }^{40}$. Ejemplo de ello es que una persona no puede vender su libertad a otra ${ }^{41}$. No obstante, no tienen un carácter absoluto, puesto que se pueden limitar ${ }^{42}$ para satisfacer otros derechos.

Ante un caso de colisión de derechos fundamentales ${ }^{43}$, por ejemplo entre la libertad de culto y la vida ${ }^{44}$, se debe limitar un derecho para satisfacer el otro. Pero dicha limitación tiene ciertas características, entre ellas, que se da sobre casos específicos, que está en cabeza del juez y que su sentencia no constituye precedente, puesto que el método elaborado para solucionar estas disputas es la ponderación, la cual se debe emplear caso a caso (Alexy, 2008b).

Recapitulando, el constitucionalismo democrático "ata las manos de las generaciones presentes para impedir que éstas amputen las manos de las generaciones futuras" (Ferrajoli, 2009, p. 96). Esto quiere decir que un pueblo puede determinarse democráticamente como le plazca, siempre y cuando no vulnere límites establecidos en la Constitución. En palabras de Holmes, "los muertos no deben gobernar a los vivos, pero sí puede facilitar el que los vivos se gobiernen a sí mismos" (Holmes, 1999, p. 262).

Por lo tanto, para que un sistema político tenga un carácter democrático, es necesario que se despoje constitucionalmente el poder que tiene la mayoría, en

40 Al respecto, véase: Diez (2001).

41 Otro ejemplo es que en el Derecho colombiano, más específicamente en materia laboral, existe una prohibición de trabajar cuarenta y ocho horas a la semana, por una cifra menor a la del salario mínimo legal mensual vigente.

42 Para Oscar Agudelo (2012),

la limitabilidad y restricción de un derecho fundamental presupone una teoría de la inexistencia de derechos absolutos y una
posición del ejercicio de los derechos fundamentales bajo límites, ya que de ser absolutos los derechos fundamentales el
legislador no tendría competencia para determinar su alcance y el límite de su ejercicio (p. 146). 43 Sobre esto, véase: Bernal (2015).

44 Este caso ha sido objeto de revisión por parte de la Corte Constitucional colombiana, mediante la Sentencia T-474 de1996. 
cuanto a restringir a la minoría, de que en un futuro se convierta en mayoría ${ }^{45}$ (Ferrajoli, 2009). Esto, debido a que la principal característica de la democracia no es el libre consentimiento, ni tampoco lograr un acuerdo común total ${ }^{46}$, sino que es el libre desacuerdo (Ferrajoli, 2016), es decir, la diversidad de opiniones y apreciaciones.

Finalmente, no sobra resaltar que "la única forma de tomarse en serio los derechos básicos de una democracia es sustrayéndolos del sentir mayoritario, a través de la adopción de cartas constitucionales que les otorguen mayor estabilidad pese al desacuerdo sobre estos" (Virgüez, 2015, p. 18).

\section{Conclusiones}

1. El constitucionalismo democrático se sitúa como una posición intermedia entre la dicotomía democracia vs constitucionalismo, involucrando elementos de ambos. Por un lado, blinda la democracia a través de herramientas como los precompromisos constitucionales y la rigidez constitucional, con el objetivo de evitar que se dé el establecimiento de un régimen antidemocrático. Por el otro, enfatiza en que el límite al interés democrático se encuentra en la Constitución misma y en los derechos fundamentales. Esto es, que un pueblo se pude gobernar a sí mismo como le plazca, siempre y cuando, a través de sus decisiones, no restrinja ni vulnere derechos fundamentales, ni tampoco se generen escenarios antidemocráticos.

2. Los mecanismos democráticos, como el referendo de la senadora Morales, no pueden limitar los derechos fundamentales, debido a que estos se erigen como una garantía individual que tiene el ciudadano frente al Estado. Sin embargo, los derechos fundamentales no poseen un carácter absoluto, debido a que en determinadas situaciones, como lo son una colisión entre dos de estos derechos, el operador judicial tiene la potestad de limitar uno para satisfacer otro, siempre y cuando acuda a herramientas que permitan que su decisión sea justificada de manera razonable.

45 Sobre esto véase la esfera de lo no decidible en Ferrajoli (2008). 
3. La calificación de los intereses democráticos en viciados o no viciados depende de si estos vulneran o no derechos fundamentales, si van en contravía de principios fundamentales de la Constitución y si los mismos llevan a situaciones antidemocráticas. De tal modo que si se enmarcan por lo menos en alguno de estos tres puntos, se consideran como viciados y, por lo tanto, no deben producir consecuencias jurídicas. Empero, si no se encuadran dentro de ninguno de estos puntos, no existe razón para limitarlos.

4. La figura del precompromiso constitucional, por sí misma, no garantiza que su contenido sea loable y que, por lo tanto, deba protegerse. Ese sería el caso de un Estado que tiene como derecho fundamental la potestad de poseer esclavos y que, sin embargo, para garantizar la plausibilidad del mismo, dicha figura deba ir unida con una concepción de justicia.

5. La rigidez es un pilar de la democracia constitucional, debido a que las normas constitucionales, al tener una superioridad jerárquica frente a las demás normas que integran el sistema jurídico, deben tener un mecanismo de modificación mucho más complejo. A su vez, esta situación fortalece la democracia, debido a que al hacer más complejo el proceso de reforma constitucional, se imponen límites a intereses democráticos transitorios, como los populismos.

\section{Referencias}

Agudelo, O. (2012). Restricción, limitabilidad y derechos fundamentales: aportes para una teoría sistemática de los derechos fundamentales como derechos limitables. En E. Castro, Crítica y Fundamentación de la Política y los Derechos Humanos (pp. 143-164). Bogotá: Universidad Libre.

Agudelo, O. \& Prieto, M. (2016). Constitucionalismo y mundos posibles. Una revisión axiomática de los precompromisos constitucionales. En O. Agudelo, Perspectivas del constitucionalismo (pp. 29-44). Bogotá: Universidad Católica de Colombia.

Agudelo, O. \& Riaño, A. (2016). Ciudadanía y nación: políticas de control fronterizo e inmigración. Novum Jus, 10(2), 57-75.

Alexy, R. (2003). Los derechos fundamentales en el Estado constitucional democrático. En M. Carbonell, Neoconstitucionalismo(s) (pp. 31-48). Madrid: Trotta.

Alexy, R. (2008a). El concepto y la naturaleza del derecho. Madrid: Marcial Pons. 
Alexy, R. (2008b). Teoría de los derechos fundamentales. Madrid: Centro de estudios políticos y constitucionales.

Alexy, R. (2009). Derechos fundamentales, ponderación y racionalidad. Revista Iberoamericana de Derecho Procesal Constitucional, (11), 3-14.

Arango, R. (2012). El concepto de derechos sociales fundamentales. Bogotá: Legis.

Benítez, V. (2012). Jueces y democracia: entre Ulises y los cantos de sirenas. Revista de la Facultad de Derecho y Ciencias Politicas. UPB, 42(117), 359-391.

Bernal, C. (2013). Unconstitutional constitutional amendments in the case study of Colombia: an analysis of the justification and meaning of the constitutional replacement doctrine. International Journal of Constitutional Law, 11(2), 339-357.

Bernal, C. (2014). El principio de proporcionalidad y los Derechos Fundamentales. Bogotá: Universidad del Externado de Colombia.

Bernal, C. (2015). La racionalidad de la ponderación. En J. Fabra \& L. García, Filosofía del derecho constitucional. Cuestiones fundamentales (pp. 409-431). México D.F.: Universidad Nacional Autónoma De México.

Bonilla, D. (2013). Toward a Constitutionalism of the Global South. En D. Bonilla, Constitutionalism of the Global South: the Activist Tribunals of India, South Africa, and Colombia (pp. 1-37). Cambridge: Cambridge University Press.

Bovero, M. (2008). Qué no es decidible. Cinco regiones del coto vedado. Doxa. Cuadernos de Filosofia del Derecho, (31), 217-225.

Brodowski, M. (2003). La estructura de los derechos fundamentales. Bogotá: Universidad del Externado de Colombia.

Brodowski, M. (2015). Propiedades calicantes y cualificantes de los derechos fundamentales. En J. Fabra \& L. García, Filosofía del derecho constitucional. Cuestiones fundamentales (pp. 339-347). México D.F.: Universidad Nacional Autónoma De México.

Cajas, M. (2004). La reforma constitucional: límite de la Corte al Congreso. Precedente. Anuario Jurídico, 13-48.

Calsamiglia, A. (1999). Constitutionalism and Democracy. En H. Koh \& R. Slye, Deliberative Democracy and Human Rights (pp. 136-142). New Haven: Yale University Press.

Corte Constitucional colombiana, (18 de febrero de 2015). Sentencia C-071. [M.P.: Jorge Iván Palacio Palacio].

Corte Constitucional colombiana, (19 de octubre de 2005). Sentencia C-1040. [M.P.: Manuel José Cepeda Espinosa, Rodrigo Escobar Gil, Marco Gerardo Monroy Cabra, Humberto Sierra Porto, Álvaro Tafur Galvis y Clara Inés Vargas Hernández].

Corte Constitucional colombiana, (05 de diciembre de 2001). Sentencia C-1287. [M.P.: Marco Gerardo Monroy Cabra]. 
Corte Constitucional colombiana, (26 de febrero de 2010). Sentencia C-141. [M.P.: Humberto Sierra Porto].

Corte Constitucional colombiana, (18 de abril de 2012). Sentencia C-288. [M.P.: Luis Ernesto Vargas Silva].

Corte Constitucional colombiana, (04 de noviembre de 2015). Sentencia C-683. [M.P.: Jorge Iván Palacio Palacio].

Corte Constitucional colombiana, (25 de septiembre de 1996). Sentencia T-474. [M.P.: Fabio Moron Diaz].

Corte Constitucional le dijo no a la segunda reelección del presidente Álvaro Uribe. (27 de febrero de 2010). Caracol Radio. Recuperado de http://caracol.com.co/radio/2010/02/26/nacional/1267200600_959859.html.

De Felice, R. (2016). El interés superior del menor prohíbe la restricción del derecho de adopción a las solas parejas de personas heterosexuales. Revista de Derecho Privado. Universidad Externado de Colombia, (31), 385-408.

De Sousa Santos, B. (1998). De la mano de Alicia: lo social y lo político en la postmodernidad. Bogotá: Siglo del Hombre Editores.

Díez, L. (2001). Nota sobre la renuncia a los derechos fundamentales. Persona y Derecho, (45), 133-138.

Domínguez, H. (2013). Democracia deliberativa en Jürgen Habermas. Analecta política, 4(5), 301-326.

Dworkin, R. (2012). El imperio de la justicia. Barcelona: Gedisa.

Dworkin, R. (2014). Los derechos en serio. Barcelona: Ariel derecho.

Elster, J. (2000). Ulysses Unbound. Studies in Rationality, Precommitment, and Constraints. Cambridge: Cambridge University Press.

Ferrajoli, L. (2001). Los fundamentos de los derechos fundamentales. Madrid: Trotta.

Ferrajoli, L. (2006). Las garantías constitucionales de los derechos fundamentales. Doxa. Cuadernos de Filosofia del Derecho, (29), 15-31.

Ferrajoli, L. (2008). La esfera de lo indecidible y la división de poderes. Estudios Constitucionales, 6(1), 337-343.

Ferrajoli, L. (2009). Democracia constitucional y derechos fundamentales. La rigidez de constitución y sus garantías. En L. Ferrajoli, J. Moreso \& M. Atienza, La teoría del derecho en el paradigma constitucional (pp. 71-115). Madrid: Fundación Coloquio Jurídico Europeo.

Ferrajoli, L. (2016). Derechos fundamentales, democracia constitucional y garantismo. Bogotá: Ediciones jurídicas Axel. 
Fioravanti, M. (2009). Los derechos fundamentales: apuntes de historia de las constituciones. Madrid: Trotta.

Foroni, C. (2015). Constitutional precommitment and collective autonomy: can they be reconciled? Revista de Estudos Constitucionais, Hermenêutica e Teoria do Direito (RECHTD), 7(3), 235-242.

Frápolli, M.J. (1 de abril de 2012). Alternancia. Periódico IDEAL. Recuperado de http://www.ugr. es/ frapolli/ALTERNANCIA.pdf.

Gargarella, R. (1997). La dificultad de defender el control judicial de las leyes. Isonomía: Revista de Teoría y Filosofia del Derecho, (6), 55-70.

Gargarella, R. (2006). ¿Democracia deliberativa y judicialización de los derechos sociales? Perfiles Latinoamericanos, (28), 9-32.

Gargarella, R. (2011). La justicia frente al gobierno. Sobre el carácter contramayoritario del poder judicial. Quito: Corte Constitucional para el Período de Transición.

Gargarella, R. (2015). Waldron, J. (2016) Political Political Theory. Cambridge: Harvard University Press. Derecho y Crítica Social, 2(1), 115-124.

Garzón, E. (1989). Algo más acerca del «coto vedado». Doxa. Cuadernos de Filosofía del Derecho, (6), 209-213.

Gasiorowski, M. \& Power, T. (1998). The Structural Determinants of Democratic Consolidation. Comparative Political Studies, 31(6), 740-771.

Gómez, J. (2012). Reformas inconstitucionales a la constitución: ¿Un caso agravado de la tensión entre la democracia y el constitucionalismo? Análisis Político, 25(75), 67-88.

Habermas, J. (2005). Facticidad y validez. Madrid: Trotta.

Harel, A. \& Kahana, T. (2015). El centro de la argumentación fácil a favor del control de constitucionalidad de la legislación. En J. Fabra \& L. García, Filosofía del derecho constitucional. Cuestiones fundamentales (pp. 295-325). México D.F.: Universidad Nacional Autónoma De México.

Holmes, S. (1999). El precompromiso y la paradoja de la democracia. En J. Elster \& R. Slagstad, Constitucionalismo y democracia (pp. 217-262). México D.F.: Fondo de Cultura Económica.

Homero. (2006). Odisea. Barcelona: Editorial Gredos.

Jefferson, T. (2004). Political Writings. Cambridge: Cambridge University Press.

Kelsen, H. (1995). Teoría general del derecho y del Estado. México D.F.: Universidad Nacional Autónoma De México.

Kelsen, H. (2001). La garantía jurisdiccional de la constitución (La justicia constitucional). México, D. F.: Universidad Nacional Autónoma De México. 
Kelsen, H. (2009). ¿Quién debe ser el defensor de la constitución? En C. Schmitt \& H. Kelsen, La polémica Schmitt/Kelsen sobre la justicia constitucional: el defensor de la constitución vs ¿Quién debe ser el defensor de la constitución? (pp. 289-366). Madrid: Tecnos.

La carta de los cristianos al Congreso (5 de mayo de 2017). Revista Semana. Recuperado de http://www.semana.com/nacion/articulo/ carta-iglesias-cristianas-al-congreso-referendo-adopcion-viviane-morales/524273.

Linares, S. (2008). La (i)legitimidad democrática del control judicial de las leyes. Madrid: Marcial Pons.

Lincoln, A. (19 de noviembre de 1863). Discurso de Gettysburg. Recuperado de http://libertad.org/ discursos/abraham-lincoln-discurso-de-gettysburg/.

Locke, J. (1988). Two Treatises of Government. Cambridge: Cambridge University Press.

Loewenstein, K. (1937). Militant Democracy and Fundamental Rights. American Political Science Review, 31(3), 417-432.

Lozano, A. (2008). La Alemania Nazi: 1933-1945. Madrid: Marcial Pons.

Mackinnon, C. \& Posner, R. (1997). Derecho y pornografía. Bogotá: Siglo del Hombre Editores.

Marbury vs Madison. 1803. Ponente John Marshall. (2006). En J. González \& M. Beltrán, Las sentencias básicas del Tribunal Supremo de los Estados Unidos de América (pp. 93-121). Madrid: Boletín Oficial del Estado y Centro de Estudios Políticos y Constitucionales.

Martínez, R. (2014). El debate sobre la naturaleza del poder constituyente: elementos para una teoría de la Constitución democrática. En R. Martínez, Teoría y práctica del poder constituyente (pp. 67-119). Valencia: Tirant Lo Blanch.

Mejía, O. (1996). La teoría del derecho y la democracia en Jürgen Habermas: en torno a "Factizität und Geltung". Ideas y Valores, 46(103), 32-52.

Mejía, O. (1998). Derecho, legitimidad y democracia deliberativa. Bogotá: Temis.

Mejía, O. (2008). Desarrollos postrawlsianos de la filosofía política contemporánea: republicanismo, marxismo analítico y democracia deliberativa. Ciencia Politica, 3(5), 143-172.

Moreso, J. (1997). La indeterminación del derecho y la interpretación de la constitución. Madrid: Centro de Estudios Políticos y Constitucionales.

Moreso, J. (1998). Sobre el alcance del precompromiso. Discusiones, (1), 95-107.

Moreso, J. (2009). La Constitución: modelo para armar. Madrid: Marcial Pons.

Nino, C. (2013). Fundamentos de derecho constitucional. Análisis filosófico, jurídico y politólogo de la práctica constitucional. Buenos Aires: Editorial Astrea.

Nussbaum, M. (2014). Una revisión de "Liberalismo político". Revista Derecho del Estado, (32), 5-33.

Paine, T. (1995). Rights of Man Common Sense and Other Political Writings. Oxford: Oxford University Press. 
Peces-Barba, G. (1995). Curso de derechos fundamentales: Teoría general. Madrid: Universidad Carlos III de Madrid. Boletín Oficial del Estado.

Pulido, F. (2017). La validez de los procedimientos de reforma constitucional fast track. International Law, Revista Colombiana de Derecho Internacional, (30), 151-184.

Rawls, J. (2006). Teoría de la justicia. México, D. F.: Fondo de Cultura Económica.

Rawls, J. (2011). Liberalismo político. México D.F.: Fondo de Cultura Económica.

RedacciónPolítica(28demarzode2016).ListaslasfirmasdelreferendodeVivianeMoralescontraadopción igualitaria. El Espectador. Recuperado de http://www.elespectador.com/noticias/ politica/listas-firmas-del-referendo-de-viviane-morales-contra-a-articulo-624145.

Redacción Política (10 de mayo de 2017). Se hundió referendo de Viviane Morales, el No ganó en tercer debate. El Espectador. Recuperado de https://www.elespectador.com/noticias/politica/ se-hundio-referendo-de-viviane-morales-el-no-gano-en-tercer-debate-articulo-693218.

Redacción Vida (12 de abril de 2017). Colombia, entre los diez países más católicos del mundo. El Tiempo. Recuperado de http:/www.eltiempo.com/colombia/otras-ciudades/ colombia-es-uno-de-los-diez-paises-mas-catolicos-del-mundo-77648.

Sant'Ana Pedra, A. (2010). Un análisis sobre la intangibilidad de las cláusulas pétreas. Derechos y Libertades: revista de filosofia del derecho y derechos humanos, (22), 241-250.

Schmitt, C. (1996). Teoría de la constitución. Madrid: Alianza Editorial.

Schmitt, C. (2004). Legality and Legitimacy. Durham: Duke University Press.

Schmitt, C. (2009). El defensor de la constitución. En C. Schmitt \& H. Kelsen, La polémica Schmitt/ Kelsen sobre la justicia constitucional: el defensor de la constitución vs ¿Quién debe ser el defensor de la constitución? (pp. 1-287). Madrid: Tecnos.

Stuart, J. (1878). El gobierno representativo. Sevilla: Universidad de Sevilla, Biblioteca Científico-literaria.

Virgüez, S. (2015). Democracia, desacuerdo y derecho constitucional. Una revisión a la tensión entre constitucionalismo y democracia en el debate Dworkin-Waldron. Revista de Derecho Público. Universidad de los Andes, (35), 1-31.

Waldron, J. (1993). A Right-Based Critique of Constitutional Rights. Oxford Journal of Legal Studies, 13(1), 18-51.

Waldron, J. (2004). Deliberación, desacuerdo y votación. En R. Slye \& H. Koh, La democracia deliberativa y derechos humanos (pp. 249-268). Barcelona: Gedisa.

Waldron, J. (2005). Derecho y desacuerdos. Madrid: Marcial Pons.

Waldron, J. (2015). El centro de la argumentación contra el control judicial de la legislación. En J. Fabra \& L. García, Filosofía del derecho constitucional. Cuestiones fundamentales (pp. 151-218). México D.F.: Universidad Nacional Autónoma de México. 
Waldron, J. (2018). El control judicial le cuesta demasiado a la democracia. 171-182. (L. García, \& V. Benítez, Entrevistadores) Isonomía. Revista de Teoría y Filosofía del Derecho, (48).

Williams, P. (2003). La dolorosa prisión del lenguaje de los derechos. En W. Brown \& P. Williams, La crítica de los derechos (pp. 43-73). Bogotá: Siglo del Hombre Editores. 